\section{Killing or caring?}

\section{As the New England Journal of Medicine publishes the Groningen protocol for euthanasia in severely ill newborn babies, Tony Sheldon talks to its author, Eduard Verhagen}

"It's time to be honest. All over the world doctors end lives discreetly, out of compassion." With these words Eduard Verhagen, clinical director of paediatrics at University Medical Centre Groningen, in the Netherlands, gained international notoriety.

He has sparked a professional debate over whether, in exceptional cases, it is humane to kill extremely sick newborn babies if medical treatment cannot alleviate their suffering. His study of Dutch practice, published this week in the New England Journal of Medicine and previously in the Dutch Journal of Medicine, offers a unique and challenging insight into a reality of modern medicine (New England Journal of Medicine 2005;352:959; Nederlands Tijdschrift Geneeskunde 2005;149:1838).

Verhagen asks, "If I have no techniques, no options to treat, if palliative care is not an option, what do I do? Do I send the child away, or really help it and hasten its death?

"We are not making this up. Horrible diseases do exist where a child is suffering unbearably but will not die immediately."

Last autumn he attempted to make politicians in The Hague take notice by revealing that a joint local protocol had been drawn up by paediatricians and the public prosecution service in Groningen under which paediatricians who deliberately ended the lives of neonates would not be prosecuted for murder if they followed strict criteria. Verhagen then called for a national protocol and a multidisciplinary committee to advise in such cases

Within weeks he had become an international hate figure. Doctors in Groningen were painted as barbarians proud of killing babies, and the Vatican compared the doctors' practices to those of the Nazis.

Yet within the Netherlands there was less fury. Verhagen's call is just the latest act in a long debate.

The 1994 "euthanasia reporting" law required doctors to report when they deliberately end the lives of newborns. But although research indicates that doctors probably end the lives of about 15 newborn babies a year, on average only three are reported.

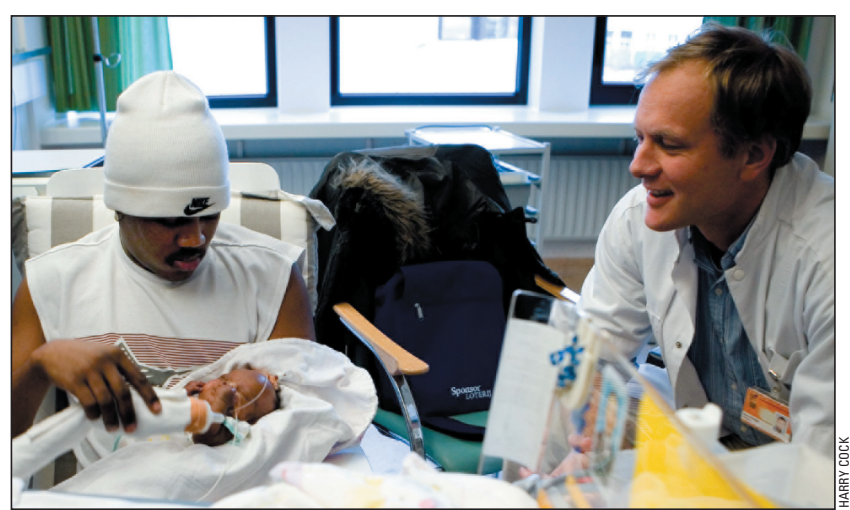

Dr Eduard Verhagen says: "We are dealing with death on a neonatal intensive care ward every day"

No cases have come to court since the legal test cases against gynaecologist Henk Prins and general practitioner Gerhard Kadijk in the mid-1990s. Both doctors were acquitted because the newborns were suffering hopelessly and there was no possibility that their suffering could be reduced by responsible medical means.

Also, it has long been accepted by many Dutch paediatricians that the deaths of extremely sick newborn babies are sometimes hastened by doctors. During the 1990s first the Dutch Paediatric Society, then the Royal Dutch Medical Association, and finally a government appointed committee all produced reports acknowledging cases of newborns where it was better not to treat them, to stop treatment, or, in the worst cases, to "deliberately terminate" life. This led in 1997 to the government's promise to set up a national reporting committee. But nothing happened.

Verhagen's own desire to confront the issue was sparked by a dilemma involving a newborn baby with a severe and untreatable form of a rare inherited skin disease, epidermolysis bullosa. This causes the skin to blister on contact, which can result in infection, sepsis, and death. The child was in severe pain whenever the bandages were replaced and was unlikely to live long. The parents did not want their child to suffer. The public prosecutor said, "Do what you have to do," but gave no assurance that a murder charge would not follow. Verhagen decided that, in such circumstances, he could not help the child to die. The child was discharged and died a year later from an infection.

Meanwhile Verhagen became

ware that doctors in his department deliberately ended the lives of newborns, but in secret.

This attitude is an anathema to Verhagen. "We train 35 residents a year to become 'modern' paediatricians. That means being honest about your actions and taking responsibility for the consequences. At the same time we expect them to be silent on this?"

A desire among the public prosecution service to encourage dialogue between the legal and the medical world allowed Verhagen to act. In 2001 he invited a local magistrate to tour a neonatal intensive care ward on a normal day. Verhagen claims that the magistrate was "amazed" at what he saw. "People do not understand. It is not just about deliberately ending life. We are dealing with death on a neonatal intensive care ward every day, children are dying, decisions are being taken to stop or whether to start treatment."

The public prosecutor's office then cooperated. It provided the documentation on 22 reported cases since 1997, including four from Verhagen's own group, where paediatricians had "ended the lives" of newborns under 6 months old.

Examining the medical reports, the local advice not to prosecute, and the national decision to accept that advice, Verhagen realised that in every case the same argument was accepted. Although the newborns were not dependent on intensive care, the doctors accepted "deliberate termination of life" because of "the presence of hopeless suffering, with no means of alleviating the suffering."

Verhagen adopted the criteria used by the public prosecution service to draw up his own local protocols. These criteria included the presence of hopeless and unbearable suffering, the consent of the parents, consultation with other doctors, and the termination of life being properly carried out.

So what kind of "exceptional cases" could the estimated 15 among 200000 births a year be? The 22 reported cases were all of severe spina bifida or hydrocephalus. But Verhagen stresses that $99.9 \%$ of babies born with spina bifida are treatable and go on to lead fulfilling lives. However, different specialist teams all agree that in some cases of spina bifida involving brain damage and other congenital malformations treatment is pointless. Another example is severe hypoxia at birth where the brain, lungs, and heart are all damaged and the child may be having continual convulsions.

Critics argue that these decisions are not based exclusively on physical suffering but on other criteria as well, such as quality of life, future ability to communicate, and the chance of the child leading an independent life. Verhagen argues that all doctors already make such decisions. "We are not working in intensive care for the sake of intensive care but to be able to offer the child a better future. We are continually making decisions about a child's prospects."

By raising these issues Verhagen believes he can encourage Dutch paediatricians to report their actions, as making the decision to end a life is "the most important decision a paediatric team will ever make." He believes that by not prosecuting doctors Dutch society has already accepted deliberate killing as an option, but "the politicians are leaving the doctors to struggle on."

Tony Sheldon Utrecht 